\title{
Machine Learning Approaches for Prediction of the Compressive Strength of Alkali Activated Termite Mound Soil
}

\author{
Assia Aboubakar Mahamat ${ }^{1, *}$ (]), Moussa Mahamat Boukar ${ }^{2}$, Nurudeen Mahmud Ibrahim ${ }^{2}$,

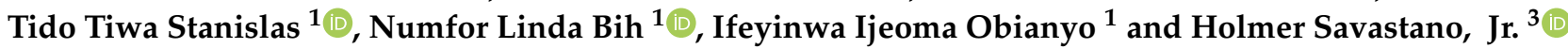 \\ 1 Department of Materials Science and Engineering, African University of Science and Technology, \\ Abuja 900100, Nigeria; stidotiwa@aust.edu.ng (T.T.S.); nlinda@aust.edu.ng (N.L.B.); \\ obianyo@aust.edu.ng (I.I.O.) \\ 2 Department of Computer Science, Faculty of Natural and Applied Sciences, Nile University of Nigeria, \\ Abuja 900100, Nigeria; musa.muhammed@nileuniversity.edu.ng (M.M.B.); \\ nurudeen.ibrahim@nileuniversity.edu.ng (N.M.I.) \\ 3 Department of Biosystems Engineering, Research Nucleus on Materials for Biosystems NAP BioSMat, \\ University of Sao Paulo, Sao Paulo 13635-900, Brazil; holmersj@usp.br \\ * Correspondence: aassia@aust.edu.ng
}

check for updates

Citation: Mahamat, A.A.; Boukar, M.M.; Ibrahim, N.M.; Stanislas, T.T.; Linda Bih, N.; Obianyo, I.I.; Savastano, H., Jr. Machine Learning Approaches for Prediction of the Compressive Strength of Alkali Activated Termite Mound Soil. Appl. Sci. 2021, 11, 4754. https://doi.org/10.3390/app11114754

Academic Editor: Carlos Thomas

Received: 17 March 2021

Accepted: 6 May 2021

Published: 22 May 2021

Publisher's Note: MDPI stays neutra with regard to jurisdictional claims in published maps and institutional affiliations.

Copyright: (c) 2021 by the authors. Licensee MDPI, Basel, Switzerland. This article is an open access article distributed under the terms and conditions of the Creative Commons Attribution (CC BY) license (https:// creativecommons.org/licenses/by/ $4.0 /)$.
Featured Application: The potential application of the work is to facilitate the perception of the properties of unconventional construction materials. That implies the correlation between the various constituent during the prediction.

Abstract: Earth-based materials have shown promise in the development of ecofriendly and sustainable construction materials. However, their unconventional usage in the construction field makes the estimation of their properties difficult and inaccurate. Often, the determination of their properties is conducted based on a conventional materials procedure. Hence, there is inaccuracy in understanding the properties of the unconventional materials. To obtain more accurate properties, a support vector machine (SVM), artificial neural network (ANN) and linear regression (LR) were used to predict the compressive strength of the alkali-activated termite soil. In this study, factors such as activator concentration, $\mathrm{Si} / \mathrm{Al}$, initial curing temperature, water absorption, weight and curing regime were used as input parameters due to their significant effect in the compressive strength. The experimental results depict that SVM outperforms ANN and LR in terms of $\mathrm{R}^{2}$ score and root mean square error (RMSE).

Keywords: machine learning; artificial neural network; support vector machine; linear regression; alkali-activated termite soil; compressive strength

\section{Introduction}

Over the last decade, a global shift has been noticed in the field of construction. The requirements are oriented in terms of eco-friendliness, renewability, cost, availability, reliability and sustainability for construction materials. These requirements are driven by the concern for the protection of the ecosystem, to reduce $\mathrm{CO}_{2}$ emission and use wastes for repairing [1], upgrading and constructing [2]. Most of the research effort are directed towards innovating empirical and traditional materials for construction through modern and sustainable technologies; thus, there is interest in earth-based materials [2-5]. Earth-based materials have long been used empirically as a construction material, among them being termite mound clay [6]. Termite mound soil (TMS) is the soil obtained from the anthill [7-16]; it is spread abundantly around the tropics [17] but considered as waste [18-24]. Additionally, in the construction field experimental tasks are time consuming, very expensive and some properties cannot be easily modelled due to the complex relationship between the mechanical properties and the constituents. 
In order to minimize the experimental tasks and increase the accuracy of data, researchers focused on the use of artificial intelligence (AI) models which are similar to the human brain [25] and capable of solving very complex variables [26,27]. Machine learning (ML) is a subset of AI used to anticipate and evaluate various properties of construction materials. Henceforth, ML approaches have gained a lot of interest in construction applications to predict the structural behavior of different elements. In addition, data processing indicated a high efficiency performance because the outputs can be predicted using the inputs without knowing their correlations [28]. ML models consist of computer algorithms capable of generating (anticipating) patterns and hypotheses through a provided dataset for future values. They have been proven to be effective in saving time, cost, their ability to satisfy the requirements of various design codes, standards [29] and future applications. ML techniques can accurately predict the behavior of materials [30] although the relationships between the input and output are nonlinear [29] or not easily modeled [31]. In the prediction of concrete behavior, artificial neural networks (ANN), support vector machines (SVM), decision trees, and evolutionary algorithms (EA) are the four models that are mainly used [29].

In Naderpour's et al. (2018) work, they utilized back-propagation ANN to predict the compressive strength of recycled aggregate concrete (RAC). They obtained very accurate regression values for the training, validation and testing of $0.903,0.89$ and 0.829 , respectively [31]. Meanwhile, the study conducted by Chopra et al. (2016), utilized ANN methods to comparatively examine the compressive strength of concrete. Their study was a comparative examination of the ANN and genetic programming (GP) to ascertain and compare the accuracy of both techniques in the prediction of the compressive strength of concrete [32]. Aref et al. (2018) investigated the use of natural pozolonna from Syria in concrete. They explored the strength and durability of Syrian volcanic scoria and predicted the mechanical behavior using an ANN and multiple linear regression (MLR). From the models they used, they found out that the ANN displayed higher accuracy. They concluded by highlighting the contribution of the volcanic scoria in the reduction in the concrete's permeability and its effect on durability-related properties too [33], whereas Chithra et al. (2016) carried out a comparative study between ANN and MLR for predicting the compressive strength of concretes containing nanosilica and copper slag [26].

Perk et al. (2019) predicted concrete's strength using support vector machine (SVM) and ANN models. During their prediction, they correlated wave velocities to the mechanical properties, meaning that they used three types of ultrasonic velocities as input parameters. The SVM models resulted in more accurate results due to the over-fitting issues observed in ANN models [34]. In Bonifácio's work, the prediction of the mechanical properties of light weight aggregate concrete (LWAC) was examined through the use of SVM and finite elements (FEM) models. Both models efficiently predicted the mechanical properties of the LWAC but the SVM displayed slightly better performance with lower average error [35]. Lu et al. (2013) investigated the important parameters to be considered when using the SVM models as they control the tradeoff between under-fitting and overfitting. They emphasized the advantage of using SVM models for small sizes of sample sets. Hence, efficient learning from a limited number of samples that is very important in shortening the material's developments cycle [36]. Yuantian's (2020) study used six different ML algorithms, among which was SVM, to develop a hybrid technique in estimating the compressive strength of jet grouting composite. They compared the different techniques based on their accuracy and concluded that SVM models performed better [28].

The work carried out by Obianyo et al. (2020) utilized multivariate models, namely linear regression, nonlinear regression and mixed models. The multivariate models were used to predict the compressive strength of lateritic soil stabilized with agro-waste. They selected three independent variables to elucidate their effect on the compressive strength. They concluded that the linear models performed better than nonlinear; meanwhile, the mixed models performed better than the two previous [37]. Sadrmomtazi (2013) used regression to model the compressive strength of expanded polystyrene concrete. They 
found that the regression model can be ideally used to assess the durability of the expanded polystyrene concrete [38]. The simple logistic regression is a common classification technique and is a useful method for solving the binary classification problem. Another category of classification is multinomial classification, which handles the issues where multiple classes are present in the target variable.

This study intends to develop ANN, SVM and LR models to predict the mechanical behavior of alkali-activated termite soil bricks. In this study, six input characteristics, namely $\mathrm{Si} / \mathrm{Al}$, initial curing temperature, activator concentration, water absorption, curing regime and weight, were used to predict the compressive strength. Si / Al in alkali-activated materials is a key component that controls the particles binding, and thus commands mechanical behavior (macrostructure). The initial curing temperature controls the period of the chemical reactions taking place, while the curing regime determines the route of the chemical reactions during the curing period. Water absorption partially determines the dimensional integrity of the alkali-activated termite soil (AATS). Additionally, the variation of these characteristics facilitates the prediction of the optimal compressive strength. ANN, SVM and LR models can be divided into training, validation, and testing. The training set is used to train the models. Validation data provide an evaluation of the models' fit on the training data to prevent the models over fitting and also to stop the training when the error increases. The models are finally applied on the experimental data to predict the compressive strength of the alkaline-activated termite soil (AATS).

The subsequent sections of this investigation are organized as follows: Section 1 provides a brief review of the different literature using ML algorithms to predict the behavior of construction materials plus the knowledge contribution of this paper. In Section 2, the materials used and experimental program are presented with a brief description of the models used in this investigation. In Section 3, the applications and results obtained from the various models used are presented. In Section 4, focal conclusions from this study are presented.

\section{Statement of the Originality and Significance}

The training and testing data for artificial neural network (ANN), support vector machine (SVM) and linear regression (LR) models' development were prepared from experimental primary datasets carried out during this investigation. To the author's knowledge, most of the papers using ML approaches use secondary data (data from the previously published literature). Therefore, the current study uses primary data to facilitate reproducibility. Direct comparison with existing literature on termite mound soil was not made due to the inexistence of published literature in the prediction of termite soil performance using ML techniques. Subsequently, this study pioneers the use of ML techniques to predict the behavior/performance of unconventional construction materials such as termite mound soil.

\section{Materials and Methods}

In this study, termite soil (TS) was collected from a construction site in Abuja, Nigeria. The anthills were spread in the region, without any utilization and were about to be demolished due to their location in that construction field. The anthill was deserted by the ants and the hills' age ranged from 5 to 15 years old. The physical properties of the anthills differed from one to the other; their height varied from $50 \mathrm{~cm}$ to $2 \mathrm{~m}$ while their mineralogical composition did not vary significantly. The soil was obtained by breaking down the hills, grinding and sieving the soil into finer particles. X-Ray fluorescence (XRF) analysis was conducted using the Thermo Scientific Epsilon Spectrometer to access the mineral composition of the TS. Furthermore, electron dispersive spectroscopy (EDX) was used to obtain its chemical composition and Fourier transform infrared analysis was used to detect the molecular bonding existing between the particles. The physical characteristics of the termite soil and alkali activator are presented in Table 1. 
Table 1. Physical properties of the termite soil (TS) and naturally occurring alum.

\begin{tabular}{|c|c|c|c|c|c|}
\hline Atterberg Limits & Particle Size & Color & Moisture Content & Density & Specific Gravity \\
\hline $\begin{array}{c}\text { Liquid Limit }(33.51 \%) \\
\text { Plastic Limit }(22.75 \%) \\
\text { Plasticity Index }(10.76)\end{array}$ & $\begin{array}{l}\text { Clay (40\%) Sand } \\
(38 \%) \text { Silt }(22 \%)\end{array}$ & $\begin{array}{l}\text { TS (brown) Alum } \\
\text { (whitish) }\end{array}$ & $3.5 \%$ & $0.395 \mathrm{~g} / \mathrm{cm}^{3}$ & 2.59 \\
\hline
\end{tabular}

Naturally occurring alum mineral was used as the alkaline activator. The alum was obtained from a local district market at a very insignificant price. The activator was used at different concentration levels of $1 w t \%, 3 w t \%$ and $5 w t \%$ based on previous study [2]. A chemical analysis and PH determination were performed on the naturally occurring alum.

During the brick production, the powder form of the soil and the natural alum were mixed with a laboratory mechanical mixer for 5 min before the addition of potable water, as specified in the BS1377-2 [39]. The paste was poured into metallic mold of $50 \mathrm{~mm} \times 50 \mathrm{~mm} \times 50 \mathrm{~mm}$ before being oven-dried for $24 \mathrm{~h}$ prior to demolding. The produced bricks were subjected to different curing environments, from room temperature to oven-dry, for a curing period of 7, 14 and 58 days, as shown in Figure 1. To accurately predict the compressive strength of the alkali-activated termite soil (AATS), six independent variables were used: $X_{1}, X_{2}, X_{3}, X_{4}, X_{5}$ and $X_{6}$, denoting activator concentration, $\mathrm{Si} / \mathrm{Al}$, initial curing temperature, water absorption, weight and curing regime, respectively as seen in Table 2.

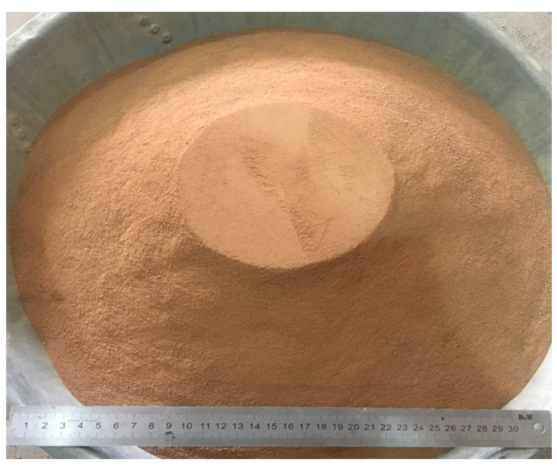

(a)

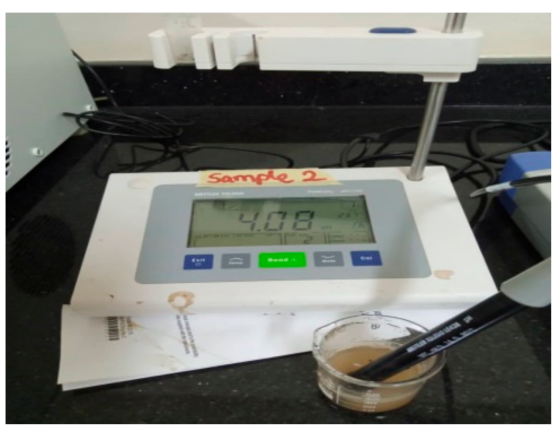

(d)

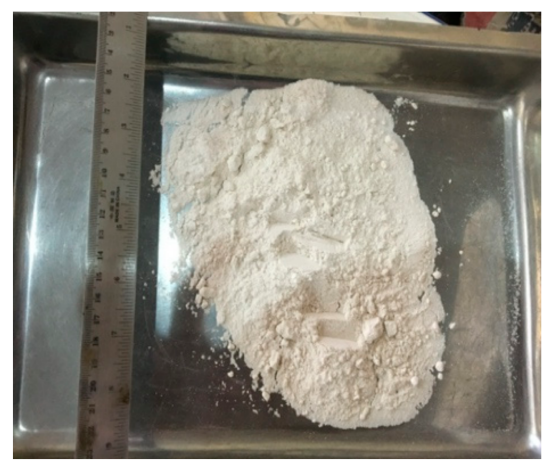

(b)

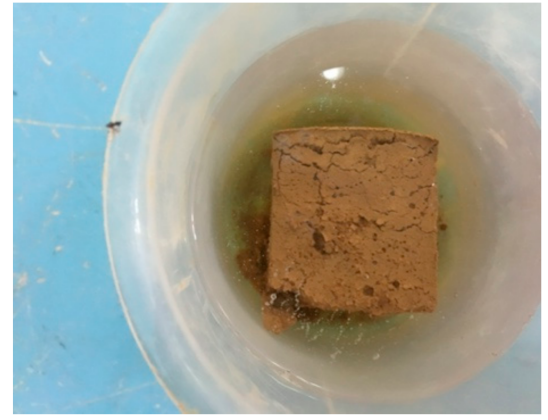

(e)

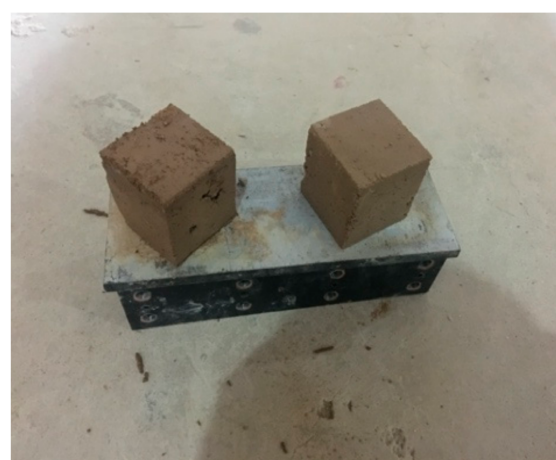

(c)

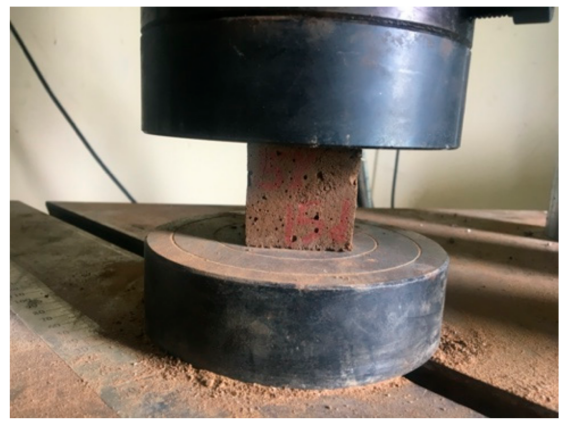

(f)

Figure 1. (a) Ground and sieved termite soil, (b) powdered natural alum, (c) cubic bricks of alkali-activated termite soil just after demolding, (d) Ph analysis of the mixture, (e) water absorption analysis of the samples and (f) compressive strength testing of the alkali-activated termite soil. 
Table 2. Details of the experimental input datasets.

\begin{tabular}{|c|c|c|c|c|c|c|}
\hline $\mathrm{Si} / \mathrm{Al}$ & Percent Activation & ICT (C) & Curing Temp (C) & Wa $(\%)$ & Weight (kg) & Strength (Mpa) \\
\hline 1.85 & 0.03 & 105 & 27 & 10.68 & 0.191 & 0 \\
\hline 1.91 & 0.03 & 60 & 27 & 13.36 & 0.189 & 0.1076 \\
\hline 1.43 & 0.03 & 105 & 27 & 0.74 & 1.86 & 0 \\
\hline 1.57 & 0.03 & 60 & 27 & 5.09 & 1.87 & 1.5796 \\
\hline 1.72 & 0.03 & 105 & 60 & 17.73 & 0.185 & 0.5264 \\
\hline 1.83 & 0.03 & 60 & 60 & 11.91 & 0.183 & 2.516 \\
\hline 1.85 & 0.03 & 105 & 27 & 10.86 & 0.191 & 0 \\
\hline 1.91 & 0.03 & 60 & 27 & 13.33 & 0.189 & 0.6084 \\
\hline 1.43 & 0.03 & 105 & 27 & 0.71 & 1.86 & 0 \\
\hline 1.57 & 0.03 & 60 & 27 & 4.88 & 1.87 & 2.7144 \\
\hline 1.72 & 0.03 & 105 & 60 & 17.07 & 0.185 & 0.246 \\
\hline 1.83 & 0.03 & 60 & 60 & 11.09 & 0.183 & 2.252 \\
\hline 1.85 & 0.03 & 105 & 27 & 10.52 & 0.191 & 1.4156 \\
\hline 1.91 & 0.03 & 60 & 27 & 13.28 & 0.189 & 1.42 \\
\hline 1.43 & 0.03 & 105 & 27 & 0.79 & 1.86 & 0.4488 \\
\hline 1.57 & 0.03 & 60 & 27 & 5.03 & 1.87 & 0.7076 \\
\hline 1.72 & 0.03 & 105 & 60 & 18.01 & 0.185 & 0.588 \\
\hline 1.83 & 0.03 & 60 & 60 & 12.58 & 0.183 & 0.1944 \\
\hline 1.85 & 0.03 & 105 & 27 & 10.48 & 0.191 & 0.05184 \\
\hline 1.91 & 0.03 & 60 & 27 & 13.55 & 0.189 & 2.3132 \\
\hline 1.43 & 0.03 & 105 & 27 & 0.82 & 1.86 & 0.696 \\
\hline 1.57 & 0.03 & 60 & 27 & 5.99 & 1.87 & 0.6688 \\
\hline 1.72 & 0.03 & 105 & 60 & 18.25 & 0.185 & 0.48 \\
\hline 1.83 & 0.03 & 60 & 60 & 12.05 & 0.183 & 0.0876 \\
\hline 1.31 & 0.05 & 105 & 60 & 1.49 & 0.189 & 3.215 \\
\hline 1.35 & 0.05 & 60 & 27 & 2.53 & 1.86 & 3.431 \\
\hline 1.99 & 0.05 & 105 & 27 & 2.45 & 1.87 & 0.78 \\
\hline 1.62 & 0.05 & 60 & 27 & 0.04 & 0.185 & 1.512 \\
\hline 1.31 & 0.05 & 105 & 60 & 1.51 & 0.183 & 4.628 \\
\hline 1.99 & 0.05 & 60 & 27 & 1.89 & 0.189 & 0.612 \\
\hline 1.62 & 0.05 & 105 & 27 & 0.13 & 1.86 & 1.416 \\
\hline 2.39 & 0.01 & 60 & 60 & 10.2 & 1.87 & 1.98 \\
\hline 3.19 & 0.01 & 105 & 27 & 1.58 & 0.185 & 0.668 \\
\hline 2.29 & 0.01 & 60 & 27 & 0.56 & 1.87 & 0.844 \\
\hline 2.39 & 0.01 & 105 & 60 & 9.98 & 0.185 & 2.147 \\
\hline 3.19 & 0.01 & 60 & 27 & 1.74 & 0.183 & 0.58 \\
\hline 2.29 & 0.01 & 105 & 27 & 0.57 & 0.191 & 0.839 \\
\hline
\end{tabular}

\subsection{Artificial Neural Network (ANN)}

The ANN operates by emulating the functionality of the neurons in the human brain. ANN mimics the memorizing and information processing activities of neuronal networks. Hence, it gives computer and information systems human-like classification and approximation capabilities [40]. ANN was used because of its capability to learn non-linear models and also its capability to learn models in real-time. A commonly used ANN is the multilayer perceptron (MLP) [41]. MLP is comprised of an input layer, one or more hidden layers and an output layer of computation node. The ANN is associated with weights which are adjusted during training to minimize classification errors [42]. It can learn a non-linear function approximator for either classification or regression. It is different from logistic regression, in that between the input and the output layer, there can be one or more non-linear layers, named hidden layers. The advantages of multi-layer perceptron are:

- The capability to learn non-linear models.

- The capability to learn models in real-time (on-line learning).

\subsection{Support Vector Machine (SVM)}

SVM is a type of machine learning algorithm that was developed by Vapnik (1998) [43]. SVMs are a set of supervised learning methods used for classification, regression and outlier detection. Due to the robust performance of SVM when dealing with noisy and sparse data, it has become a system of choice in many machine learning applications. SVM performs classification by separating data using a hyper-plane that is farthest from them (termed as 'the maximal margin hyper-plane'). The method of support vector classification can be extended to solve regression problems. This method is named support vector regression (SVR). The model produced by support vector classification (as described above) depends only on a subset of the training data, because the cost function for building the model does not care about training points that lie beyond the margin. Analogously, the model 
produced by SVR depends only on a subset of the training data, because the cost function ignores samples whose prediction is close to their target. The advantages of support vector machines are:

- Effective in high dimensional spaces, high speed, possibility for continuous re-training with new information.

- Still effective in cases where the number of dimensions is greater than the number of samples.

- Uses a subset of training points in the decision function (named support vectors), so it is also, memory efficient.

Versatile: different Kernel functions can be specified for the decision function. Common kernels are provided, but it is also possible to specify custom kernels.

\subsection{Linear Regression (LR)}

LR is one of the simplest and commonly used ML algorithms for two-class classification. It is easy to implement and can be used as the baseline for any binary classification problem. Linear regression (LR) describes and estimates the relationship between one dependent binary variable and independent variables. It is a predictive algorithm which uses independent variables to predict the dependent variable [44]. The advantage of linear regression is that the model finds the two parameters that minimize the error between predictions and the true regression targets on the training set. Both ANN and linear regression were used, mainly for the purpose of comparison with the support vector machine (SVM).

\subsection{Regression Analysis}

Regression is the measure of the average relationship between two or more variables in terms of the original units of the data. It also attempts to establish the nature of the relationship between variables; that is, to study the functional relationship between the variables and thereby provide a mechanism for prediction or forecasting. A scatter diagram can be used to show the relationship between two variables. Regression analysis is used to:

- Predict the value of a dependent variable based on the value of at least one independent variable.

- Explain the impact of changes in an independent variable (the variable used to explain the dependent variable) on the dependent variable (the variable we wish to predict or explain).

\subsection{Metrics}

The performance of the models can be appraised by various validation methods. In this study, the validation methods used are namely the coefficient of determination $\left(R^{2}\right)$ and root mean square (RMSE). These validation methods are used to examine the prediction's accuracy; subsequently, the $R^{2}$ is used to correlate the inputs and outputs [45]. If its value is close to 1 , this indicates that a good fitting of the model, while the value close to 0 indicates a bad fitting of the model [46]. Additionally, the RMSE is used to evaluate the error that emerged during the training, testing and validating. The $\mathrm{R}^{2}$ and RMSE were calculated as described in Wassim's work [29].

\subsection{Experimental Setup}

The experiment was implemented in Python 2.7.12. The hardware configuration used for the implementation environment was Intel Core (TM) i5-4790 CPU, 3.60 GHz and 4GB RAM. The parameters used for the SVM are shown in Table 3. For ANN and LR, the default parameters were used. 
Table 3. Parameter settings for SVM.

\begin{tabular}{cc}
\hline Parameter & Value \\
\hline Kernel & linear \\
$\mathrm{C}$ & 1 \\
\hline
\end{tabular}

\section{Results}

Scanning electron micrographs (SEM) of TS and AATS of 14 days are presented in Figure 2. From the microstructural observations, the morphology of the samples tends to change after alkali activation as the particles tend to flocculate under the effect of the natural $\mathrm{KOH}$ from the activator. This is confirmed by the energy dispersive spectroscopy (EDX) results, where the formation of new elements has been noticed (.a.i and b.i). Moreover, the Fourier transform infrared (FTIR) results in (.a.ii and b.ii) indicate that the molecular bonds were not significantly transformed. However, shifts in the absorption peaks were noticed. The shift of the peaks is mainly attributed to the O-H and Si-O-Si functional group resulting in the formation of new bands during the activation. Results of the compressive strength development reveals an increase in the compressive strength from the early curing age for all the samples. This can be explained by the lower rate of alkalinity consumption in the early stage. However, at the late curing period, the samples showed a complete difference in the trend than the previously observed trend. A possible explanation is that the alkalinity consumption rate was higher at the late ageing, which means the $\mathrm{PH}$ of the samples tends to be lower over the time. Besides, the samples containing the activator presented higher compressive strength with curing days for the various curing regimes. As expected, the thermal effect was observed on all the bulk performances (samples cured initially at high temperature). This could be explained by the temperature effect in the gel formation during the chemical reactions taking place between the precursor (TMS) and the activator (natural alum).

Figure 3 shows the results of the models developed to predict the compressive strength. These results demonstrate that the testing, training and validation of all the three (3) models were successful. However, the results of the statistical measures (as seen in Figure 4) reveals that the SVM exhibited the highest $\mathrm{R}^{2}(70 \%)$. Low $\mathrm{R}^{2}$ and RMSE of $63 \%$ and 0.7 , respectively, were displayed by the ANN. Meanwhile, the LR displayed an $\mathrm{R}^{2}$ and RMSE of $26 \%$ and 0.95 , respectively. Moreover, results obtained from the LR in terms of $R^{2}$ differed significantly from the ANN and SVM models, indicating the weak correlation between the input and output given by the model. The highest $\mathrm{R}^{2}$ was obtained from the SVM model, pointing out the accuracy of the model in establishing the interdependence between the input and compressive strength of the AATS. These results align with the previous work carried out by Chou et al.; in their study, they found out that the SVM displayed the best performance over the ANN and MR [47]. In addition, the RMSE displayed by all the models indicates the insignificance of the errors that arose from the prediction models during the training. However, the LR exhibited an RMSE of 0.95, indicating the near inexistence of errors during the training. Furthermore, the SVM and ANN also displayed an RMSE higher than 0.5 ( 0.6 and 0.7 , respectively).

Figure 4 shows the results of the regression analysis for all three techniques. In Figure $4 a$, it is observed that the SVM outperforms ANN and LR in terms of $\mathrm{R}^{2}$ score, where the SVM achieves an $R^{2}$ of $70 \%$ while the ANN and LR achieves an $R^{2}$ of $63 \%$ and $26 \%$, respectively. In terms of RMSE, the SVM outperforms the ANN and LR as shown in Figure $4 \mathrm{~b}$ where the SVM records an RMSE of 0.6 while the ANN and LR records an RMSE of 0.7 and 0.95 , respectively. 


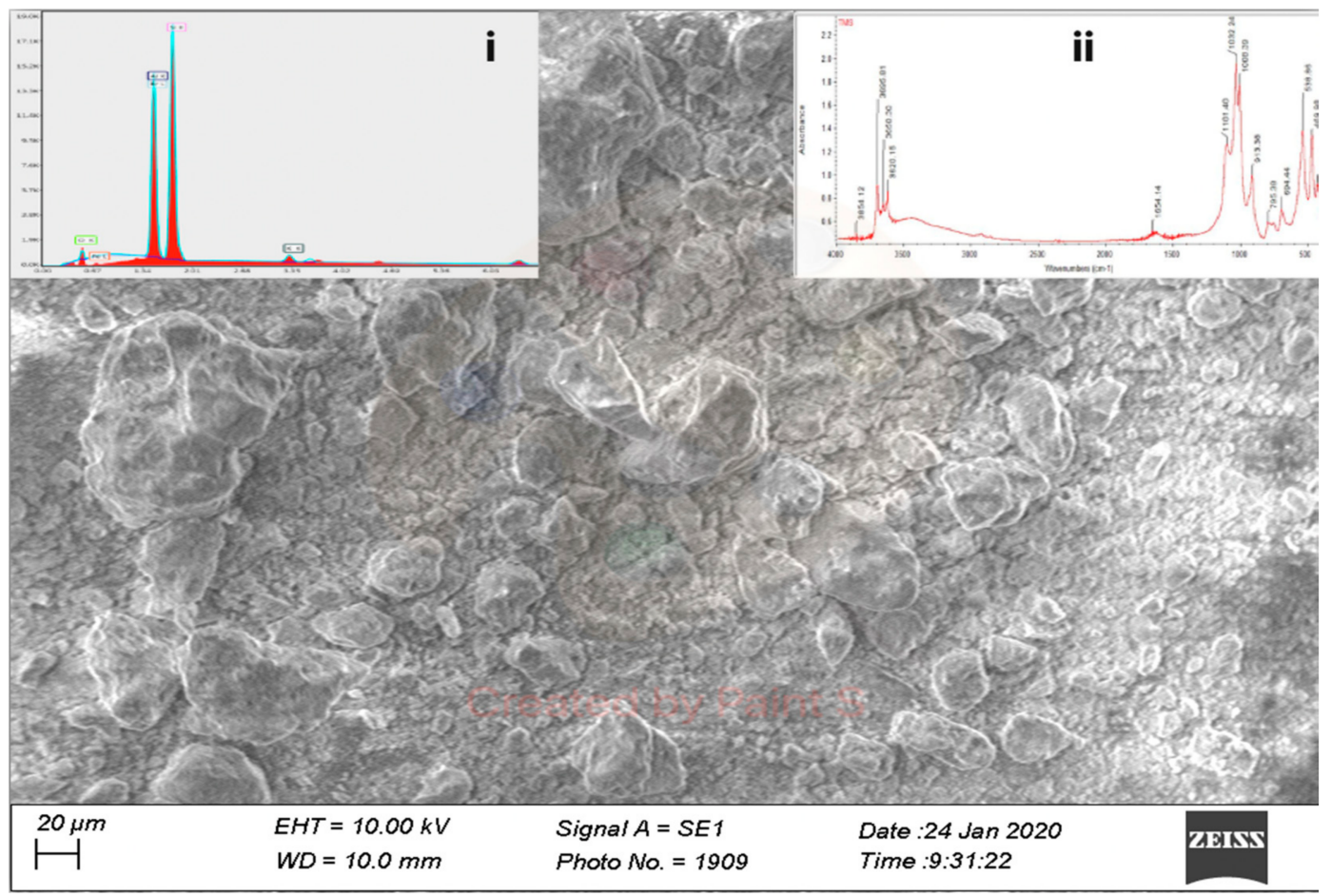

(a)
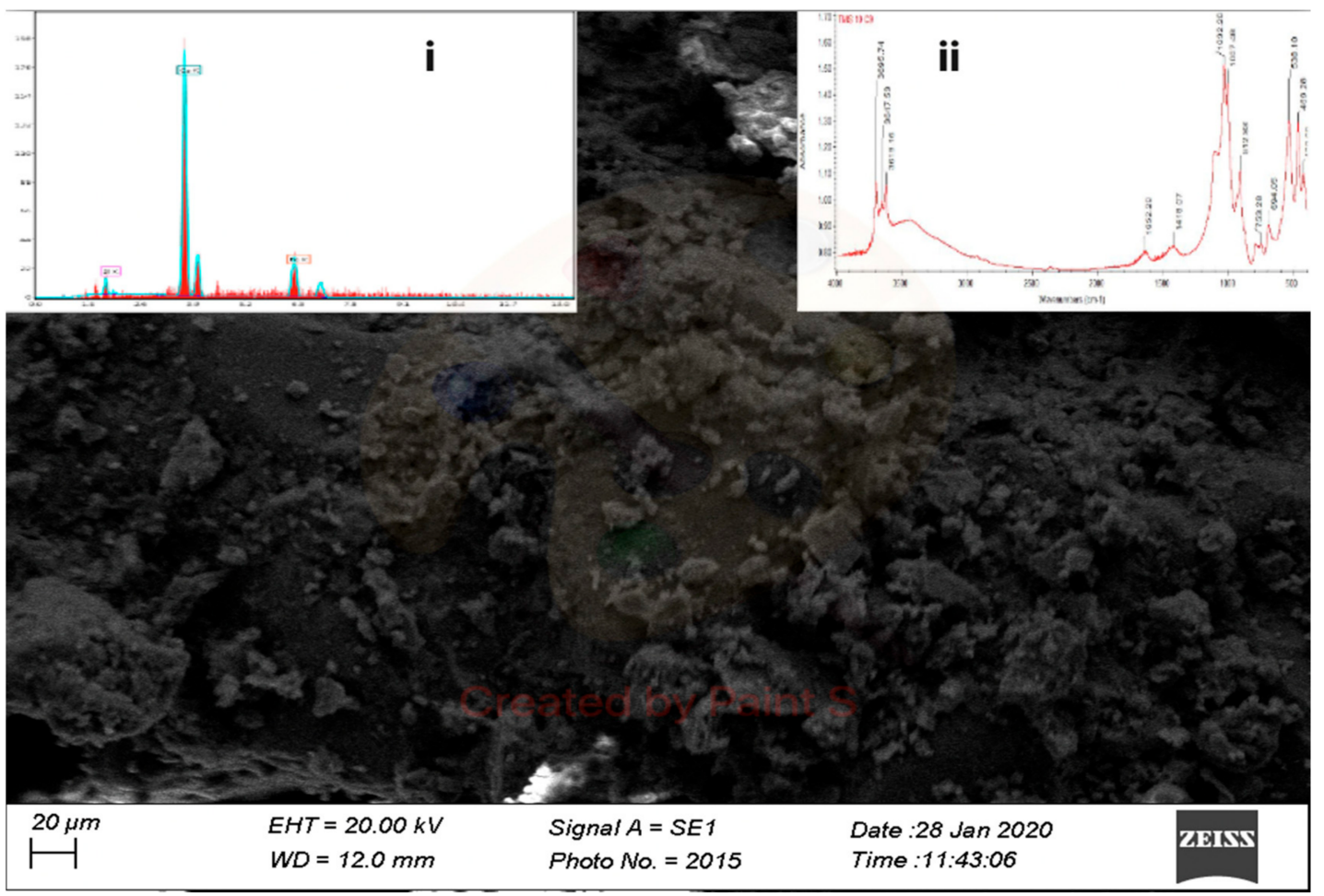

(b)

Figure 2. Scanning electron micrographs (SEM) with the chemical component obtained from the attached energy dispersive spectroscopy (EDX) and the various molecular bonding extracted from fourier transform infrared (FTIR) characterizations of (a) raw termite mound soil and (b) alkali-activated termite soil. 


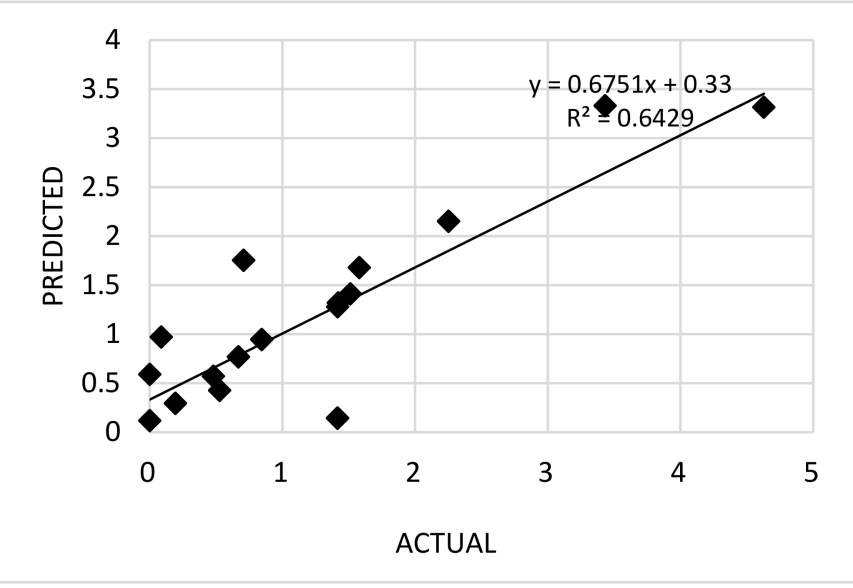

(a)

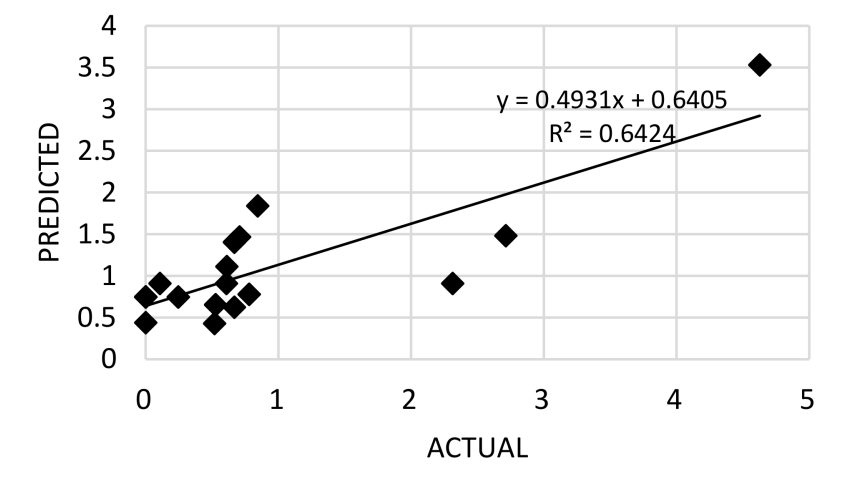

(c)

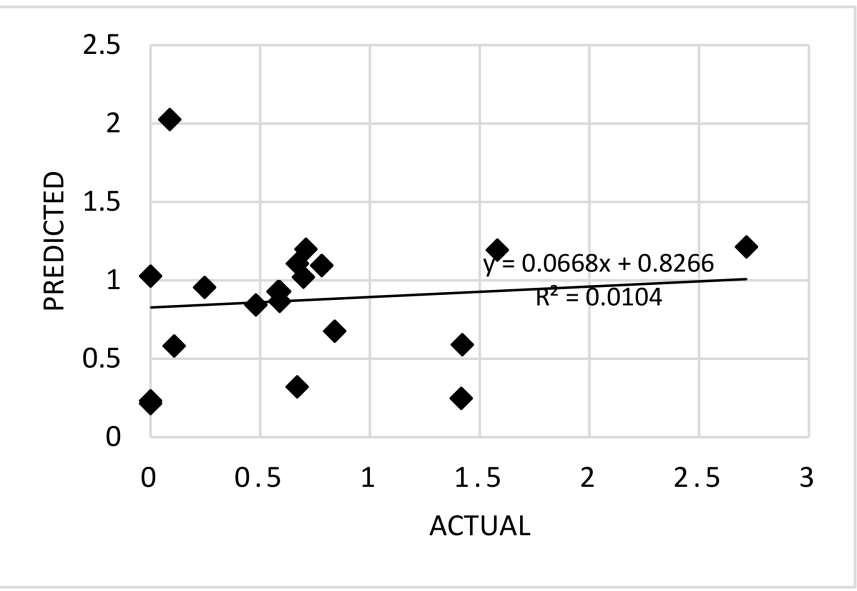

(b)

Figure 3. Predicted values vs. actual values from the models: (a) SVM, (b) LR and (c) ANN.

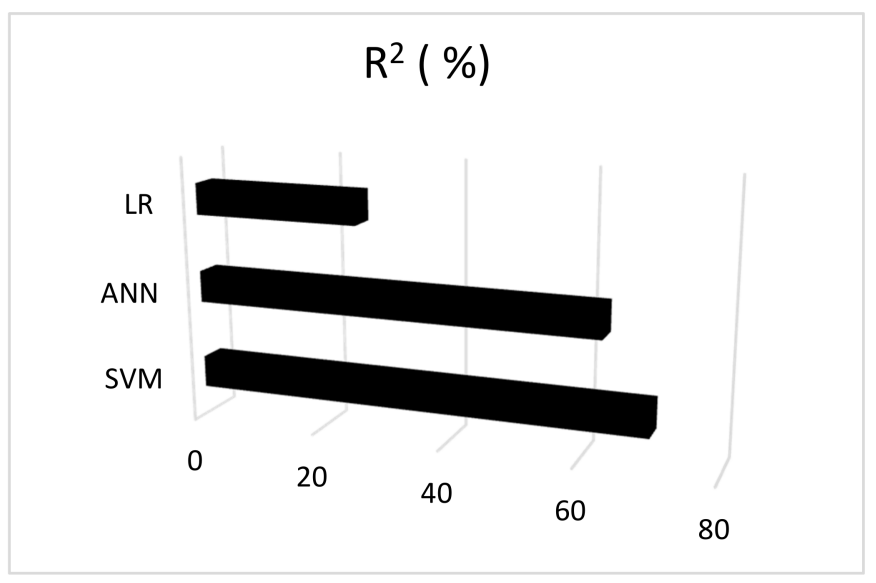

(a)

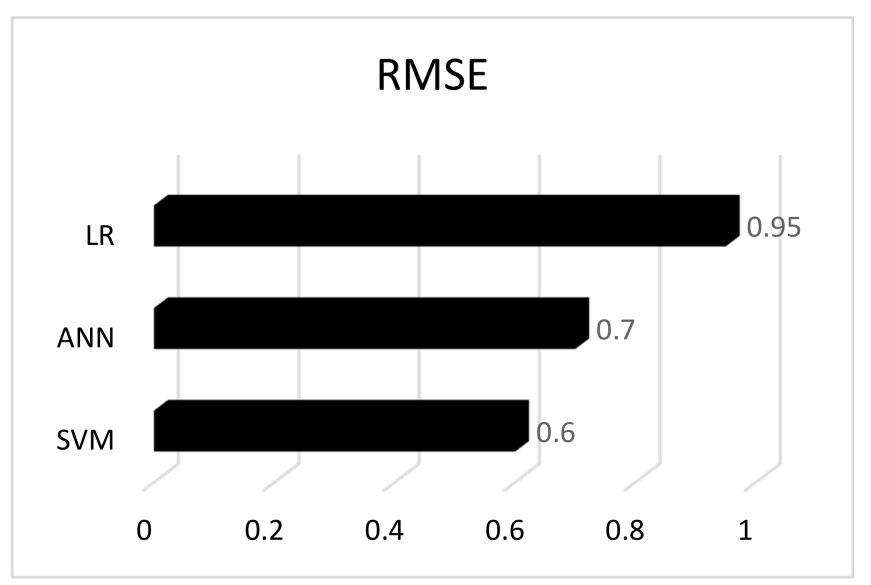

(b)

Figure 4. Statistical measures of the prediction models: (a) coefficient of determination $\left(\mathrm{R}^{2}\right)$ and $(\mathbf{b})$ root mean square (RMSE). 


\section{Discussion}

Analysis of the result shows that the SVM algorithms demonstrated a superior performance in terms of both $\mathrm{R}^{2}$ score and RMSE. This result stems from the fact that the SVM has a robust performance relative to the ANN and LR because the SVM employs the maximal margin hyper plane in predicting the correlation between the features (ICT, curing temp, weight, etc.) and the compressive strength of the AATS. In addition, the SVM only uses a subset of training points which are highly correlated with the dependent variable (strength) in the decision function (named support vectors); consequently, the SVM is capable of eliminating noise which may hamper the prediction result and therefore only the attributes that are highly linked with the AATS strength will be employed for prediction. The ANN performs relatively poorly because with the ANN, different random weight initializations can lead to different validation accuracy. Additionally, the ANN requires tuning a number of hyper parameters such as the number of hidden neurons, layers, and iterations. The linear regression has the lowest performance in terms of both $R^{2}$ score and RMSE because the coefficient estimates for LR rely on the interdependence of the features. When features are correlated and the columns of the design matrix $\mathrm{X}$ have an approximate linear dependence, the design matrix becomes close to singular and as a result, the least-squares estimate becomes highly sensitive to random errors in the observed target, producing a large variance which could result in a high RMSE and a low coefficient of determination $\left(R^{2}\right)$.

Additionally, the statistical values displayed by each model corroborate that the prediction of the AATS compressive strength with the SVM model is singularly accurate. This is inconsistent with results obtained from the prediction of volcanic scoria-based concrete [33]. However, the results from the present study align with the results obtained using the SVM in the prediction of light weight aggregate concrete (LWAC) [35]. Nonetheless, due to the inexistence of the literature on the prediction of the AATS compressive strength, the results cannot be compared appropriately because of the difference in the materials used. Thus, the comparison was made with similar materials such as the scoria used in the previous reference. The resemblance of the scoria with the termite soil is that both materials are classified as natural pozzolanas. Furthermore, it is worth recalling that the various statistical measures and results obtained peaked the importance and effect of the input parameters on the compressive strength.

\section{Conclusions}

In this paper, the applicability of SVM, ANN and LR models for the prediction of alkali-activated termite soil's compressive strength were explored. It was demonstrated that the developed models were successfully trained and validated based on the experimental dataset. The three models developed were compared based on their accuracy. The following focal conclusions can be drawn:

- Termite mound soil is an unconventional earth-based material, classified as natural pozzolanas. Its activation through naturally occurring alum is aimed to produce eco-friendly and locally available construction materials. Subsequently, the novelty of these materials makes the application of ML techniques a useful tool to appraise their properties with a variation of constituents.

- The correlation between the input parameters and the output feature displayed by the coefficient of determination $\mathrm{R}^{2}(70 \%, 63 \%$ and $26 \%$ ) indicates that the three models are suitable for modeling the compressive strength of the AATS dataset.

- The SVM model displayed the higher coefficient of determination (70\%) and a root mean square of 0.6 . These values indicate the accuracy of the model in predicting the compressive strength of the AATS based on the given input parameters.

- The ANN exhibited the second-best performance, with a coefficient of determination of $63 \%$ and a root mean square of 0.7 .

- LR demonstrated the lower accuracy, with a coefficient of determination of $26 \%$ and a root mean square of 0.95 . A lower mean square error is desirable; a high RMSE 
signifies higher error. Therefore, the SVM and ANN perform better since they have a low RMSE compared to LR.

The higher accuracy and suitability of the SVM model made it more desirable than the ANN and LR methods in the prediction of the AATS compressive strength. In addition to the high accuracy, the usage of the SVM model contributes to reduce time-consuming laboratory experiments, resulting in the reduction in the general cost and time during the properties' investigations. The regression analysis showed that all studied parameters in this work have considerable effects on the properties of the AATS. However, more analysis can be performed in future investigations to determine the most influential parameter.

For future work, the applicability of the ML methods can be used to assess the properties of new unconventional materials with questionable features such as new mixture constituents. In addition, the experiment was conducted with small scale data. In future research, it is recommended to expand the data scale in order to examine the performance of the algorithms with large scale data in the domain.

Author Contributions: Conceptualization, A.A.M., M.M.B. and N.L.B.; methodology, A.A.M., M.M.B. and H.S.J.; software, N.M.I.; supervision, M.M.B. and H.S.J.; visualization, T.T.S., I.I.O. and H.S.J.; writing—original draft, A.A.M., N.M.I., T.T.S., N.L.B. and I.I.O.; writing—review and editing, N.M.I., T.T.S., N.L.B. and I.I.O. All authors have read and agreed to the published version of the manuscript.

Funding: This research was funded by the Pan African Materials Institute (PAMI) under the World Bank, African Centers of Excellence (ACE) program held by the African University of Science and Technology (AUST) with the grant number AUST/PAMI/2015/5415-NG.

Institutional Review Board Statement: Not applicable.

Informed Consent Statement: Not applicable.

Data Availability Statement: The data presented in this study are available on request from the corresponding author after obtaining permission of authorized person.

Conflicts of Interest: The authors declare no conflict of interest.

\section{References}

1. Bih, N.L.; Mahamat, A.A.; Hounkpè, J.B.; Onwualu, P.A.; Boakye, E.E. The Effect of Polymer Waste Addition on the Compressive Strength and Water Absorption of Geopolymer Ceramics. Appl. Sci. 2021, 11, 3540. [CrossRef]

2. Provis, J.L.; van Deventer, J.S.J. RILEM State-of-the-Art Reports State-of-the-Art Report, RILEM TC 224-AAM. Available online: http:/ / www.springer.com/series/8780 (accessed on 16 November 2020).

3. Falah, M.; Obenaus-Emler, R.; Kinnunen, P.; Illikainen, M. Effects of Activator Properties and Curing Conditions on AlkaliActivation of Low-Alumina Mine Tailings. Waste Biomass Valorization 2020, 11, 5027-5039. [CrossRef]

4. Zhang, Z.; Wang, H.; Yao, X.; Zhu, Y. Effects of halloysite in kaolin on the formation and properties of geopolymers. Cem. Concr. Compos. 2012, 34, 709-715. [CrossRef]

5. Mahamat, A.A.; Obianyo, I.I.; Ngayakamo, B.; Bih, N.L.; Ayeni, O.; Azeko, S.T.; Savastano, H., Jr. Alkali activation of compacted termite mound soil for eco-friendly construction materials. Heliyon 2021, 7. [CrossRef]

6. Ojo, E.B.; Mustapha, K.; Teixeira, R.S.; Savastano, H. Development of unfired earthen building materials using muscovite rich soils and alkali activators. Case Stud. Constr. Mater. 2019, 11. [CrossRef]

7. Dhembare, A.J. Physico-Chemical Properties of Termite Mound Soil. Available online: www.scholarsresearchlibrary.com (accessed on 28 December 2020).

8. Nwakonobi, T.; Anyanwu, C.; Tyav, L. Effects of rice husk ash and termite hill types on the physical and mechanical properties of burnt termite clay bricks for rural housing. Glob. J. Pure Appl. Sci. 2015, 20, 57. [CrossRef]

9. Anigbogu, N. Properties of Compressed Earth Bricks Stabilized with Termite Mound Material. Available online: http:/ /www. researchgate.net/publication/235910056 (accessed on 20 September 2020).

10. Kandasami, R.K.; Borges, R.M.; Murthy, T.G. Effect of biocementation on the strength and stability of termite mounds. Environ. Geotech. 2016, 3, 99-113. [CrossRef]

11. Akinyemi, B.A.; Omoniyi, T.E.; Adeyemo, M.O. Prospects of coir fibre as reinforcement in termite mound clay bricks. Acta Technol. Agric. 2016, 19, 57-62. [CrossRef]

12. Gandia, R.M.; Corrêa, A.A.R.; Gomes, F.C.; Marin, D.B.; Santana, L.S. Physical, mechanical and thermal behavior of adobe stabilized with 'synthetic termite saliva'. Eng. Agric. 2019, 39, 139-149. [CrossRef]

13. Corrêa, A.A.; Bufalino, L.; Protásio, T.D.P.; Ribeiro, M.X.; Wisky, D.; Mendes, L.M. Evaluation of Mechanical Properties of Adobe Chemically Stabilized with "Synthetic Termite Saliva". Key Eng. Mater. 2014, 600, 150-155. [CrossRef] 
14. Mujinya, B.B.; Mees, F.; Erens, H.; Dumon, M.; Baert, G.; Boeckx, P.; Ngongo, M.; Ranst, E.V. Clay composition and properties in termite mounds of the lubumbashi area, D.R. congo. Geoderma 2013, 192, 304-315. [CrossRef]

15. Millogo, Y.; Hajjaji, M.; Morel, J.C. Physical properties, microstructure and mineralogy of termite mound material considered as construction materials. Appl. Clay Sci. 2011, 52, 160-164. [CrossRef]

16. Faria, O.B.; Battistelle, R.A.G.; Neves, C. Influence of the addition of 'synthetic termite saliva' in the compressive strength and water absorption of compacted soil-cement. Ambiente Construído 2016, 16, 127-136. [CrossRef]

17. Mahamat, A.A.; Linda Bih, N.; Ayeni, O.; Azikiwe Onwualu, P.; Savastano, H.; Oluwole Soboyejo, W. Development of Sustainable and Eco-Friendly Materials from Termite Hill Soil Stabilized with Cement for Low-Cost Housing in Chad. Buildings 2021, 11, 86. [CrossRef]

18. Jouquet, P.; Traoré, S.; Choosai, C.; Hartmann, C.; Bignell, D. Influence of termites on ecosystem functioning. Ecosystem services provided by termites. Eur. J. Soil Biol. 2011, 47, 215-222. [CrossRef]

19. Ganguli, A.K.; Kumar, S.; Baruah, A.; Vaidya, S. Nanocrystalline silica from termite mounds. Curr. Sci. 2014, 106, 83-88.

20. Van Huis, A. Cultural significance of termites in sub-Saharan Africa. J. Ethnobiol. Ethnomed. 2017, 13, 8. [CrossRef]

21. Pomeroy, D.E. The Distribution and Abundance of Large Termite Mounds in Uganda. J. Appl. Ecol. 1977, 14, 465-475. [CrossRef]

22. Ackerman, I.L.; Teixeira, W.G.; Riha, S.J.; Lehmann, J.; Fernandes, E.C.M. The impact of mound-building termites on surface soil properties in a secondary forest of Central Amazonia. Appl. Soil Ecol. 2007, 37, 267-276. [CrossRef]

23. Sarcinelli, T.S.; Schaefer, C.E.G.R.; Lynch, L.D.S.; Arato, H.D.; Viana, J.H.M.; Filho, M.R.D.A.; Gonçalves, T.T. Chemical, physical and micromorphological properties of termite mounds and adjacent soils along a toposequence in Zona da Mata, Minas Gerais State, Brazil. Catena 2009, 76, 107-113. [CrossRef]

24. Jean-Pierre, B.; Moise, A.A.A.; Sylvain, T.C.; Philippe, K.K.; Yao, T.; Ahoua, Y.; Mauricette, Q.N.S.W. Spatial distribution and Density of termite mounds in a protected habitat in the south of Cote d'Ivoire: Case of national floristic center (CNF) of UFHB of Abidjan. Eur. Sci. J. 2015, 11.

25. Boukar, M.M.; Muslu, I. Administration and academic staff performance management system using content management system (cms) technologies. In Proceedings of the International Conference on Electronics, Computer and Computation (ICECCO), Ankara, Turkey, 7-8 November 2013.

26. Chithra, S.; Kumar, S.R.R.S.; Chinnaraju, K.; Ashmita, F.A. A comparative study on the compressive strength prediction models for High Performance Concrete containing nano silica and copper slag using regression analysis and Artificial Neural Networks. Constr. Build. Mater. 2016, 114, 528-535. [CrossRef]

27. Yazid, A.B.; Boukar, M.M.; Ibrahim, S.Y.; Muslu, I. Four-Factors Authentication Algorithm for Preventing Fake Attendance. In Proceedings of the 15th International Conference on Electronics, Computer and Computation (ICECCO), Abuja, Nigeria, 10-12 December 2019.

28. Sun, Y.; Li, G.; Zhang, J. Developing hybrid machine learning models for estimating the unconfined compressive strength of jet grouting composite: A comparative study. Appl. Sci. 2020, 10, 1612. [CrossRef]

29. Chaabene, W.B.; Flah, M.; Nehdi, M.L. Machine learning prediction of mechanical properties of concrete: Critical review. Constr. Build. Mater. 2020, 260, 119889. [CrossRef]

30. Idris, M.K.; Boukar, M.M.; Adeshina, S.A. Analysis of bad roads using smart phone. In Proceedings of the 15th International Conference on Electronics, Computer and Computation (ICECCO), Abuja, Nigeria, 10-12 December 2019. [CrossRef]

31. Naderpour, H.; Rafiean, A.H.; Fakharian, P. Compressive strength prediction of environmentally friendly concrete using artificial neural networks. J. Build. Eng. 2018, 16, 213-219. [CrossRef]

32. Chopra, P.; Sharma, R.K.; Kumar, M. Prediction of Compressive Strength of Concrete Using Artificial Neural Network and Genetic Programming. Adv. Mater. Sci. Eng. 2016, 2016. [CrossRef]

33. Al-Swaidani, A.M.; Khwies, W.T. Applicability of Artificial Neural Networks to Predict Mechanical and Permeability Properties of Volcanic Scoria-Based Concrete. Adv. Civ. Eng. 2018, 2018. [CrossRef]

34. Park, J.Y.; Yoon, Y.G.; Oh, T.K. Prediction of concrete strength with P-, S-, R-wave velocities by support vector machine (SVM) and artificial neural network (ANN). Appl. Sci. 2019, 9, 4053. [CrossRef]

35. Bonifácio, A.L.; Mendes, J.C.; Farage, M.C.R.; Barbosa, F.S.; Barbosa, C.B.; Beaucour, A.L. Application of support vector machine and finite element method to predict the mechanical properties of concrete. Lat. Am. J. Solids Struct. 2019, 16. [CrossRef]

36. Lu, W.C.; Ji, X.B.; Li, M.J.; Liu, L.B.; Yue, B.H.; Zhang, L.M. Using support vector machine for materials design. Adv. Manuf. 2013, 1, 151-159. [CrossRef]

37. Obianyo, I.I.; Anosike-Francis, E.N.; Ihekweme, G.O.; Geng, Y.; Jin, R.; Onwualu, A.P.; Soboyejo, A.B.O. Multivariate regression models for predicting the compressive strength of bone ash stabilized lateritic soil for sustainable building. Constr. Build. Mater. 2020, 263, 120677. [CrossRef]

38. Sadrmomtazi, A.; Sobhani, J.; Mirgozar, M.A. Modeling compressive strength of EPS lightweight concrete using regression, neural network and ANFIS. Constr. Build. Mater. 2013, 42, 205-216. [CrossRef]

39. British Standards Institution. British Standard Methods of Test for Soils for Civil Engineering Purposes; British Standards Institution: London, UK, 1990.

40. Chen, T.C.T.; Liu, C.L.; Lin, H.D. Advanced artificial neural networks. Algorithms 2018, 11, 102. [CrossRef] 
41. Huynh, A.T.; Nguyen, Q.D.; Xuan, Q.L.; Magee, B.; Chung, T.; Tran, K.T.; Nguyen, K.T. A machine learning-assisted numerical predictor for compressive strength of geopolymer concrete based on experimental data and sensitivity analysis. Appl. Sci. 2020, 10, 7726. [CrossRef]

42. Kandiri, A.; Sartipi, F.; Kioumarsi, M. Predicting Compressive Strength of Concrete Containing Recycled Aggregate Using Modified ANN with Different Optimization Algorithms. Appl. Sci. 2021, 11, 485. [CrossRef]

43. Vapnik, V. The Support Vector Method of Function Estimation. In Nonlinear Modeling; Springer: Boston, MA, USA, 1998; pp. 55-85.

44. Khandelwal, R. Quick and Easy Explanation of Logistic Regression A Simple Explanation of Logistic Regression, Why We Need It, How to Evaluate Its Performance and Build a Multi-Class Classification Using Logistic Regression in Python. Available online: https: / / towardsdatascience.com/quick-and-easy-explanation-of-logistics-regression-709df5cc3f1e (accessed on 17 March 2021).

45. Bui, D.T.; Hoang, N.-D.; Nhu, V.-H. A swarm intelligence-based machine learning approach for predicting soil shear strength for road construction: A case study at Trung Luong National Expressway Project (Vietnam). Eng. Comput. 2019, 35, 955-965. [CrossRef]

46. Anysz, H.; Brzozowski, L.; Narloch, W.K.P. Feature importance of stabilised rammed earth components affecting the compressive strength calculated with explainable artificial intelligence tools. Materials 2020, 13, 2317. [CrossRef]

47. Chou, S.J.; Chiu, C.K.; Al-Taharwa, I.; Farfoura, M. Optimizing the Prediction Accuracy of Concrete Compressive Strength Based on a Comparison of Data-Mining Techniques. J. Comput. Civ. Eng. 2011, 25, 242-253. [CrossRef] 